\title{
Neonatal colonic perforation
}

\author{
Fatma Saraç, Emel Ataoğlu², Cihad Tatar ${ }^{3}$, Halil Uğur Hatipoğlu², Latif Abbasoğlu ${ }^{4}$
}

\section{ABSTRACT}

'Clinic of Pediatric Surgery, Haseki Training and Research Hospital, İstanbul, Turkey

${ }^{2}$ Clinic of Pediatrics, Haseki Training and Research Hospital, İstanbul, Turkey

${ }^{3}$ Clinic of General Surgery, Haseki Training and Research Hospital, İstanbul, Turkey ${ }^{4}$ Department of Pediatric Surgery, Acıbadem University Faculty of Medicine, İstanbul, Turkey

\section{Address for Correspondence Cihad Tatar}

Clinic of General Surgery, Haseki Training and Research Hospital, İstanbul, Turkey

Phone: +90 2125294400

e-mail:

tatarcihad@gmail.com

Received: 05.01.2014

Accepted: 23.05.2014

Available Online Date: 02.09.2014

(C) Copyright 2015 by Turkish Surgical Association

Available online at

www.ulusalcerrahidergisi.org
Neonatal colonic perforation is a rarely seen condition. Plain abdominal radiography of a 28-hour newborn consulted for vomiting and bloody stool revealed the presence of subdiaphragmatic free air, which necessitated surgical exploration. Transverse colonic perforation was detected during the exploration, and subsequently, a colostomy and appendectomy were performed. The postoperative follow-up period was uneventful. Necrotizing enterocolitis, Hirschsprung disease, and mechanical obstruction are some of the causes of colonic perforation during the neonatal period. Herein, we have shared a case of colonic perforation in an asphyctic newborn delivered after prolonged labor.

Key Words: Necrotizing enterocolitis, colonic perforation, neonatal, perinatal asphyxia

\section{INTRODUCTION}

Gastrointestinal perforations during the neonatal period are most frequently seen in the small bowel. Necrotizing enterocolitis (NEC), Hirschsprung disease (HD), anorectal malformations (ARMs), and mechanical obstructions, like intestinal atresias, small left colon syndrome, meconium plaque syndrome, stercoral perforation, idiopathic perforation, cystic fibrosis, and isolated intestinal perforation, are some of the causes of colonic perforation occurring during the neonatal period (1-4).

We present a term newborn with a history of birth asphyxia secondary to prolonged labor who was referred with rectal bleeding, and vomiting after 28 postnatal hours, which progressed dramatically with resultant development of colonic perforation.

\section{CASE PRESENTATION}

The case was the first live and spontaneously delivered term newborn of a primigravida non-kin mother (28 years old) and father (30 years old). Its birth weight was $3070 \mathrm{~g}$, and the APGAR score was 7/9 (1/5 min.). Because of a history of prolonged labor, his chord blood samples were analyzed, and the measured parameters ( $\mathrm{pH}: 7.08 ; \mathrm{pCO}_{2}: 86.3 \mathrm{~mm}-\mathrm{Hg}$; lactate $10.6 \mathrm{mmol} / \mathrm{L}$ ) established the diagnosis of birth asphyxia. He was then hospitalized in the newborn unit and consulted for vomiting and rectal bleeding emerging 28 hours after birth. On physical examination, a moderately distended abdominal wall and hypoactive bowel sounds were detected, and signs of bloody and mucoid stool were noted during the digital rectal examination. The general health state of the patient deteriorated rapidly. At that time, his laboratory test results were as follows: $\mathrm{pH}: 7.35 ; \mathrm{pO}_{2}: 39 \mathrm{~mm}-\mathrm{Hg} ; \mathrm{pCO}_{2}: 44.8 \mathrm{~mm}-\mathrm{Hg} ; \mathrm{HCO}_{3}: 22 \mathrm{mEq} / \mathrm{L}$; lactate: $6.6 \mathrm{mmol} / \mathrm{L}$; Htc: 48.4\%; Hb: $17.9 \mathrm{~g} / \mathrm{dL}$; WBC: $10.300 / \mathrm{mm}^{3}$, and Plt: $275.000 / \mathrm{mm}^{3}$. His plain abdominal radiograms revealed the presence of subdiaphragmatic free air, and so, the baby was urgently operated on with the diagnosis of intestinal perforation. Surgical exploration demonstrated diffuse fecaloid material within the abdominal cavity. Intestinal loops were completely dilated and non-peristaltic. The intestinal mesentery was edematous and inflamed with petechial bleeding; foci were detected on the intestinal walls and mesentery of the colon, ileum, and ileocecal region. An area of perforation measuring 3-4 mm in width that was surrounded with a few foci of microperforations on the distal segment of the transverse colon was seen. Patchy areas of impaired blood perfusion on the transverse and descending colon, ileum, and ileocecal regions and intestinal wall erosions on the transverse and descending colon were observed.

The appendix was inflamed and edematous, and its blood circulation was impaired. The colon with a detected perforation was resected for nearly $2 \mathrm{~cm}$, and colostomy was constructed. Appendectomy was added to the procedure. His health condition remained at a stable state during the immediate postoperative period; colostomy became functional on postoperative day 1 . Oral feeding was initiated on the $10^{\text {th }}$ postoperative day, and he was discharged on postoperative day 16 without complication.

The histopathology report was as follows: colonic material; ulcerated, necrotizing, and nonspecific chronic inflammation with numerous ganglion cells infiltrating all layers of the intestinal wall; appendi- 
citis; and periappendicitis. Written informed consent was obtained from the patient's family.

\section{DISCUSSION}

Neonatal colonic perforation is a rarely seen condition with higher morbidity and mortality rates. Hirschsprung disease, $\mathrm{NEC}$, and meconium ileus are the most significant causes of colonic perforation during the neonatal period (1-4).

In $\mathrm{HD}$, intestinal perforation is seen in $3.2 \%$ to $4.4 \%$ of the cases. It is most frequently seen during the neonatal period. Areas of perforation are most often observed in the colon and appendix. In short-segment and intermediate-length HD, perforation is situated proximal to the transitional zone. However, in total colonic aganglionosis, perforation develops in an aganglionic colon, rather than the terminal ileum proximal to the aganglionic intestinal segment. Perforation related to the HD is frequently seen in long-segment cases or total colonic aganglionosis. Importantly, the transitional zone should be meticulously examined, and a stoma using an appropriate ganglionic segment should be created $(2,4,5)$.

In our case, the transitional zone could not be identified during surgical exploration. Rectal biopsy was not performed, but an abundant number of ganglion cells were detected in the resected colonic specimen.

Conditions leading to mechanical obstruction, including imperforated anus, colonic atresia, small left colon syndrome, and meconium plaque syndrome, can result in colonic perforation. Meconium ileus is one of the well-known causes of intestinal obstruction in newborns. In $12 \%-15 \%$ of patients with cystic fibrosis, meconium ileus is found. Perforation develops frequently in the mid-ileum, and colonic perforation is rarely seen $(3,6)$. However, none of these conditions was present in our case.

Necrotizing enterocolitis is mostly seen in preterm babies. Its incidence increases in inverse proportion with gestational age; $90 \%-95 \%$ of the patients have been fed before the onset of the disease. Cases with NEC seen in full-term infants constitute $10 \%$ of all cases with NEC. In these infants, generally, risk factors, including asphyxia, intrauterine growth retardation, congenital heart disease, congenital hypothyroidism, polycythemia, hyperviscosity, blood exchange, and umbilical artery catheterization, are found. In addition, NEC can develop in normal full-term infants. In preterm infants, most frequently the ileum and jejunum are involved. Intestinal mucosal injuries stemming from low-flow states or hypoxia and related bacterial invasion have been demonstrated as the most important etiological factors in the pathogenesis of NEC.

Decreased mucosal blood supply leads to hypoxic injury in intestinal mucosa cells. Progressive destruction and death of white blood cells cause impairment of the mucosal barrier, which leads to bacterial invasion. Histopathologically, coagulation necrosis, inflammation, and hemorrhagic areas are seen. Prolonged rupture of the membranes, maternal infections, fetal distress, lower APGAR score, recurrent apneic episodes, hypotension, presence of intraumbilical vascular catheter, exchange transfusion, and PDA are some of the conditions leading to low-flow states and hypoxia. In full-term infants, NEC is seen considerably at an earlier stage, which is thought to be related to prematurely initiated formula feeding $(2,4,5,7-14)$. As well as in our patient, a history of birth asphyxia secondary to prolonged labor and enteral feeding was elicited.

However, an obvious etiological factor cannot be demonstrated for idiopathic perforation of the colon. Though the role of intestinal ischemia has been frequently reported in its pathogenesis, its precise mechanism is not clear cut. In recent studies, idiopathic perforation has been defined as localized intestinal perforation unrelated to NEC.

Occasionally, it is hard to differentiate between these two conditions. Some previous studies could not demonstrate any statistically significant difference between NEC and localized/ idiopathic perforation with regard to frequency of enteral feeding, mortality rates, perforation times, and clinical presentation. Localized perforation is seen frequently in infants with low or very low birth weights. Researchers have demonstrated a correlation between localized perforation and prenatal indomethacin and intravenous dexamethasone exposure, umbilical artery catheterization, and increased leucocyte counts. None of these etiological factors was present in our case $(1,7,15,16)$.

We previously assumed a diagnosis of colonic perforation secondary to NEC, in consideration of his history of perinatal asphyxia, early start of enteral feeding, observation of colonic and ileal involvement during surgical exploration, and available histopathological findings, including ulcerating and necrotizing nonspecific inflammation infiltrating through all layers of the intestinal wall. Irrigation of distal intestinal segments of the patient was initiated, and closure of his colostomy was scheduled at 3 months postoperatively. During irrigations performed from the rectum through the distal stoma, unobstructed, easy outflow of the irrigation fluid coming from distal stoma was observed. The patient was scheduled for distal loopographic examination; however, the patient was lost to our follow-up because of the family's settlement in another city.

\section{CONCLUSION}

Necrotizing enterocolitis has onset in full-term infants at an earlier stage and frequently involves the colon. It has lower mortality rates in full-term infants when compared with preterm infants, and early diagnosis and prompt intervention are life-saving.

Informed Consent: Written informed consent was obtained from patient's parents who participated in this case.

Peer-review: Externally peer-reviewed.

Author Contributions: Concept - F.S.; Design - F.S.; Supervision - E.A., L.A.; Funding - F.S., C.T., H.U.H.; Materials - F.S.; Data Collection and/or Processing - F.S.; Analysis and/or Interpretation - F.S.; Literature Review - F.S., C.T., L.A.; Writer - F.S., C.T., L.A.; Critical Review - E.A., L.A.; Other C.T., H.U.H.

Conflict of Interest: No conflict of interest was declared by the authors.

Financial Disclosure: The authors declared that this study has received no financial support. 


\section{REFERENCES}

1. Dey N Jr, Sharma L, Sharma B, Chandra KhS, Singh KhG, Meitei AJ. Idiopathic neonatal colonic perforation- a case report. Indian J Surg 2011; 73: 214-216.

2. Komuro H, Urita Y, Hori T, Hirai M, Kudou S, Gotoh C, et al. Perforation of the colon in neonates. J Pediatr Surg 2005; 40: 1916-1919.

3. Siddiqui MM, Burge DM. Neonatal spontaneous colonic perforation due to cystic fibrosis. Pediatr Surg Int 2008; 24: 863-864.

4. Singh S, Rawat J, Wakhlu A, Kureel SN, Pandey A. Six year retrospective analysis of colonic perforation in neonates and infants: Single centre experience. Afr J Paediatr Surg 2012; 9: 102-105.

5. Khan TR, Rawat JD, Ahmed I, Rashid KA, Maletha M, Wakhlu A, et al. Neonatal pneumoperitoneum: a critical apprasial of its causes and subsequent management from a developing country. Pediatr Surg Int 2009; 25: 1093-1097.

6. Raveenthiran V. Spontaneous perforation of the colon and rectum complicating anorectal malformation in neonates. J Pediatr Surg 2012; 47: 720-726.

7. Hwang H, Murphy JJ, Gow KW, Magee JF, Bekhit E, Jamieson D. Are localized intestinal perforation distinct from necrotizing enterocolitis? J Pediatr Surg 2003; 38: 763-767.

8. Maayan-Metzger A, Itzchak A, Mazkereth R, Kuint J. Necrotizing enterocolitis in full-term infants: case-control study and review of the literature. J Perinatol 2004; 24: 494-499.
9. Ng S. Necrotizan enterocolitis in the full-term neonate. J Paediatr Child Health 2001; 37: 1-4.

10. Ostlie DJ, Spilde TL, St Peter SD, Sexton N, Miller KA, Sharp RJ, et al. Necrotizing enterocolitis in full-term infants. J Pediatr Surg 2003; 38: 1039-1042.

11. Raboei EH. Necrotizing enterocolitis in full-term neonates: is it aganglionosis? Eur J Pediatr Surg 2009; 19: 101-104.

12. Resch B, Mayr J, Kuttnig-Haim M, Reiterer F, Ritschl E, Müller W. Spontaneous gastrointestinal perforation in very -low-birthweight infants-a rare complication in a neonatal intensive care unit. Pediatr Surg Int 1998; 13: 165-167.

13. Tayman C, Tonbul A, Uras N, Kahveci H, Köseoğlu B, Tatli MM. Evaluation of risk factors for necrotizing enterocolitis in preterm infants. J Curr Pediatr 2011; 9: 7-13.

14. Yurdakok M. What is next in necrotizing enterocolitis? Turk J Pediatr 2008; 50: 1-11.

15. Bartoli F, Vasseur Maurer S, Giannoni E, Osterheld MC, Laubscher B. Focal spontaneous colic perforation in term or near-term neonates: rare and potentially insidious. Arch Pediatr 2011; 18: 408412.

16. Korakaki E, Manoura A, Hatzidaki E, Arbiros J, Vlahakis J, Valari $V$, et al. Spontaneous intestinal perforation in a full-term infant:association with infection. Minerva Pediatr 2003; 55: 289292. 